Journal of Education and Science (ISSN 1812-125X), Vol: 30, No: 3, 2021 (45-62)

Special Issue for Proceeding of $3^{\text {rd }}$ National (1 ${ }^{\text {st }}$ international conference of biology) (ICBSUM 2021) 5, 6 July

College of Education for Pure Science, University of Mosul, Mosul, Iraq.

\title{
Molecular Identification of Local Isolated Streptomyces Species from North Region soil in Iraq
}

\author{
Omar faisal Ghazi ${ }^{*}$, Safa Ismail Al-Obaidi ${ }^{2}$ \\ ${ }^{1 * 2}$ Department of biology, college of education for pure sciences, Mosul University, Mosul, Iraq \\ E-mail: ${ }^{1 *}$ omarfaisal25@gmail.com, ${ }^{2}$ dr.safaa100@uomousal.edu.iq
}

(Received May 03, 2021; Accepted June 03, 2021; Available online August 28, 2021)

DOI: 10.33899/edusj.2000.168654, () 2021, College of Education for Pure Science, University of Mosul.

This is an open access article under the CC BY 4.0 license (http://creativecommons.org/licenses/by/4.0/).

\begin{abstract}
In this study Streptomyces were isolated from 50 bacterial isolates taken from 30 soil samples, these samples were collected from various locations in Iraq's various regions. The species of Streptomyces were isolated using starch casein agar and diagnosed microscopically and morphologically by Gram staining and glass slide. The sequence analysis $16 \mathrm{~S}$ rRNA is used to report 11 Streptomyces. 10 bands of DNA gene, a result of specific polymerase chain reaction PCR, are elected from bacterial local isolates where 1000 base pairs within one volume, The PCR products of DNA samples were chosen from 11 local isolates based on nitrogenous base sequences. These organisms are revealed as a result of the study and by using DNA Blast NCBI as fellows; Streptomyces gancidicus, $S$. werraensis, $S$. griseorubens, S. hawaiiensis, S. thermocarboxydus, S. cyaneus, S. misionensis, S. bellus, S. parvulus, S. labedae,
\end{abstract}

Keywords: Streptomyces. specific PCR, Sequencing analysis

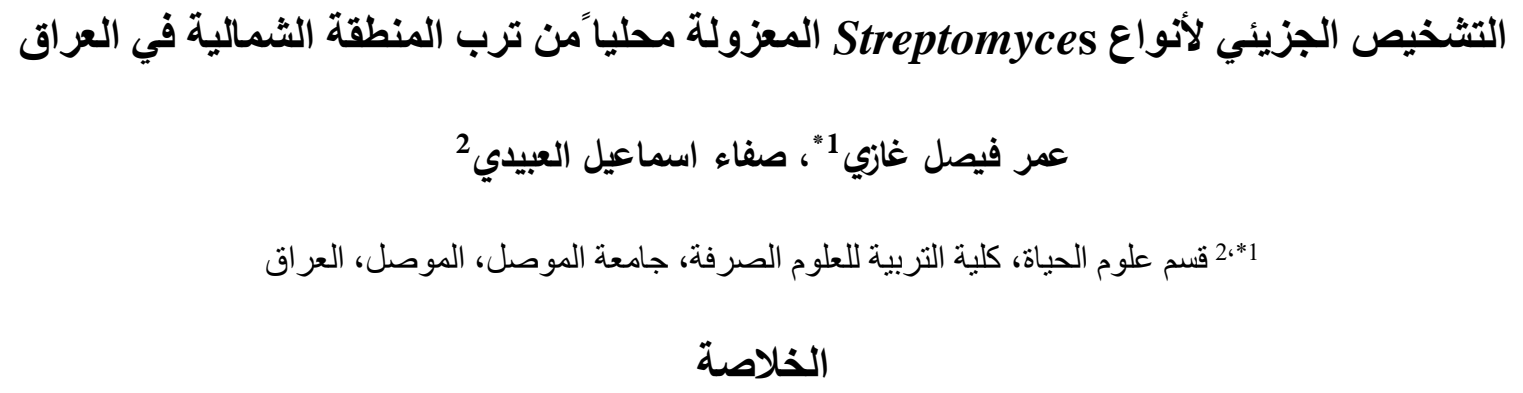

تم في هذه الدراسة ، الحصول على 50 عزلة بكتريا من جنس Streptomyces اخذت من 30 عينة تربة، جمعت من مواقع مختلفة من شمال العراق. عزلت العينات باستخدام اكار كازائين - النشأ وشخصت مايكروسكوبياً ومورفولوجياً بواسطة صبغنة كرام والثريحة الزجاجية. تحليل التتابع srRNA 16 استخدم للكثف عن 11 عزلة من جنس Streptomyces تم اختيار 10 حزم من الـ

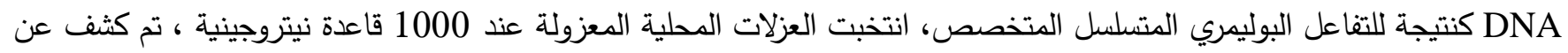
البكتريا قيد الاختبار باستخدام برنامج Streptomyces gancidicus, S. وكانت النتائج على النحو التالي: DNA Blast NCBI werraensis, S. griseorubens, S. hawaiiensis, S. thermocarboxydus, S. cyaneus, S. misionensis, S. bellus, S. parvulus, S. labedae, 
Journal of Education and Science (ISSN 1812-125X), Vol: 30, No: 3, 2021 (45-62)

Special Issue for Proceeding of $3^{\text {rd }}$ National (1 ${ }^{\text {st }}$ international conference of biology) (ICBSUM 2021) 5, 6 July

College of Education for Pure Science, University of Mosul, Mosul, Iraq.

الكلمات المفتاحية: Streptomyces- البوليمر المتسلسل المتخصص - تحليل المتتابع

\section{Introduction}

The species of streptomyces are widely prevalent in soil, It is the largest genus of the Actinomycetes, Gram-positive bacteria. Their colors mostly are grey but few are red, green, and white, while the blue is the rarest [1]. The genus Streptomyces is considered from Actinomycetes diameter (0.52) $\mu \mathrm{m}$. It is also grown Aerial mycelium carrying many spores, that are arranged in chains and take different shapes, from the spiral form, Rectus- flexibilis form, Retinaculum- Apertum form [2] [3].

The Streptomyces genus is the most important species from the group of filaments. The Novel organisms can produce secondary metabolites (Antibiotics) and (Enzyme) production used to control many pathogenic bacteria and their inhibitory impact on harmful microbes [4] [5]. The higher rate of GC is $\sim 70 \%$ of the content of Streptomyces spp. To separate Streptomyces from other bacterial such as Actinobacterial, there are distinguishing features such as 16S rDNA analysis and DNA-DNA hybridization [5] [6]. Geosmin, a scented substance produced by Streptomyces is responsible for the distinctive odor of soil.. This research aims to identify and isolate Streptomyces from the soil of northern Iraq (Nineveh, Duhok, Erbil) as well as diagnose them using microscopic and morphological experiments and a PCR test based on 16S rRNA to establish their genetic sequence. In addition, DNA Blast NCBI was used.

\section{Materials and procedures}

\section{Collecting of Samples}

Thirty soil samples were collected from various farm locations in Iraq's northern area, ranging in depth from 5 to $15 \mathrm{~cm}$, and after being collected the samples were treated with calcium carbonate $\mathrm{CaCO} 3$ (1:10) and dried at $40-45^{\circ} \mathrm{C}$ for four days. The samples were then placed in polyethylene bags and tightly sealed before being placed in the refrigerator until needed. $(1 \mathrm{gm})$ was thoroughly mixed in tubes of $15 \mathrm{ml}$ distilled water, followed by a series of dilutions until the sixth dilution was reached. On it (which was cooled to $45^{\circ} \mathrm{C}$ ), the culture medium (starch-casein medium) was filtered. and $1 \mathrm{ml}$ of the last dilution was put in a sterile petri dish. This was done three times per sample. Several solitary colonies were used for re-culture in the same medium for pure culture after the plates were selected with (10-35) colonies [7] [8] [9].

\section{Characteristics of Streptomyces}

According to Bergy's manual of systematic bacteriology, second edition, the Actinobacteria, Part A [10] . The characteristics of Streptomyces are tasted based on the pattern of formation, Gram stain, and colony morphology.

\section{Streptomyces detection}

Based on the morphology and color of the colonies, the isolates were known As well as grow on Streptomyces as well as the Tryptone yeast extract glucose Agar, Glycerol Asparagine Agar, and Nutrient Agar. The aerial and medial twigs, as well as the arrangement of spores, were studied using the Slide culture technique [11]. 


\section{The media}

\section{Starch-casein medium}

This medium was made by combining: (10 gm) starch, (0.3 gm) casein, (2 gm) KNO3, (2 gm) NaCl, (0.02 gm) CaCO3, (2 gm) KH2PO4, (0.05 gm) MgSO4.7H2O, (0.01 gm) FeSO4.7H2O, (18 gm) Agar, in 1 liter of distilled water, at a $\mathrm{pH}$ of this medium was used in isolation [12].

\section{Tryptone-yeast extract glucose agar}

The agar was made by combining (10 gm) glucose, $(3 \mathrm{gm})$ yeast extract, $(5 \mathrm{gm})$ tryptone, $(1 \mathrm{gm})$ $\mathrm{KH} 2 \mathrm{PO} 4,(1 \mathrm{gm}) \mathrm{K} 2 \mathrm{HPO} 4,(20 \mathrm{gm})$ agar in 1 liter distilled water with (7.2) pH, and sterilizing it in an autoclave [13]. This was the medium that was used to make the diagnosis..

\section{Glycerol asparagine agar medium}

This medium was prepared by mixing: (1 gm) asparagine, (10 gm) glycerol, (1 gm) $\mathrm{K}_{2} \mathrm{HPO}_{4}$, (20 gm) agar, $(1 \mathrm{ml})$ of trace salt solution, (0.64) $\mathrm{gm} \mathrm{CuSO}_{4} .5 \mathrm{H}_{2} \mathrm{O},(0.11 \mathrm{gm}) \mathrm{FeSO}_{4} .7 \mathrm{H}_{2} \mathrm{O},(0.79 \mathrm{gm})$ $\mathrm{MnCl}_{2} .4 \mathrm{H}_{2} \mathrm{O}$, and $(0.15) \mathrm{gm} \mathrm{ZnSO}_{4} .7 \mathrm{H}_{2} \mathrm{O}$, in (1 liter) of distilled water with $7.4 \mathrm{pH}$, The autoclave was used to sterilize items. This medium was used for diagnosis and isolation. [14]

\section{Czapic Dox Agar_Dox agar medium}

This medium was made by combining (30) gm sucrose, (3) gm NaNO3, (1) gm K2HPO4, (0.5 gm MgSO4, (0.5 gm KCl), (0.01) gm FeSO4, (15 gm agar) in 1 liter distilled water with a pH of 7.3, and sterilizing everything in the autoclave. [15]. This medium was used to isolate and identify the species.

\section{Nutrient agar medium}

This medium was made by melting ( $23 \mathrm{gm}$ ) of nutrient agar in (1 liter) of distilled water with a $\mathrm{pH}$ of 7.2 and sterilizing everything in the autoclave, as directed by the supplier company (Lab M Neogen Culture media). This medium was used in the isolation and identification of bacteria..

\section{DNA from Streptomyces purification and acquisition}

The DNA from the Streptomyces samples was extracted using Geneaid's kit analysis.

\section{PCR Reactions}

The Tri-EDTA (TE buffer) solution was used to fine-tune the DNA concentration in all of the isolated samples in order to achieve the optimal concentration for PCR reactions, and it worked well (50 nanogram per microliter). The master reaction for each PCR reaction was made by combining the DNA sample, the gene's specific primer, and the appender pre-mix in a $(0.2 \mathrm{ml})$ Eppendorf tube provided by the British company (bio). Using distilled water, the reaction volume was reduced to 20 microliters, and the components were then combined in a microfuge for (3-5) seconds. After that, the tubes were put in a thermal cycler to perform the polymer reactions, which were regulated by special software for each reaction. After that, the samples were electrophoresed in wells of a 2 percent agarose gel for 60-70 minutes. [3][4][16].

\section{DNA Sequencing analysis}


The most common and important method for detecting single nucleotide polymorphism (SNP) mutations and variations in DNA samples is DNA sequence analysis. On the other hand, the results of PCR reactions are used to determine the sequence of the amplified parts of DNA that will be used to find and study mut. DNA sequencing findings have recently been found to be extremely accurate in identifying mutations [5].

Furthermore, if the PCR reaction yielded more than one strand, it was purified and the desired fragment of DNA was extracted by the gel; however, if the reaction yielded just one strand, it was the main strand, and it was used to evaluate the sequences [17].

Using the method of DNA sequencing to determine the nucleotide sequences of the amplified section

The results of the PCR reaction for the samples mentioned earlier, as well as the primers, were read by a Hitachi 3130 Genetic Analyzer device, indicating that the samples used in the study are diagnosis. The genetic sequence data was linked to the National Center Biotechnology Information NCBI database., The BLAST software was used to examine the findings.

\section{Results and Discussion}

Thirty soil samples were collected from various locations in Iraq's northern region, and 50 Streptomyces samples were isolated. The samples were chosen based on the colonies' chalky appearance in the media and the wet soil (earthy odor) the smell of rain. [18][19]. The addition of CaCO3 to the soil at a ratio of 1:10 and a temperature of 40-45 $0 \mathrm{C}$ has a significant impact drying the soil inhibits the growth of vegetative bacteria, and adding $\mathrm{CaCO} 3$ raises the $\mathrm{pH}$, inhibiting the growth of fungi, enabling thread-like bacteria (Streptomyces) to thrive in the primary isolation [20][21][22].

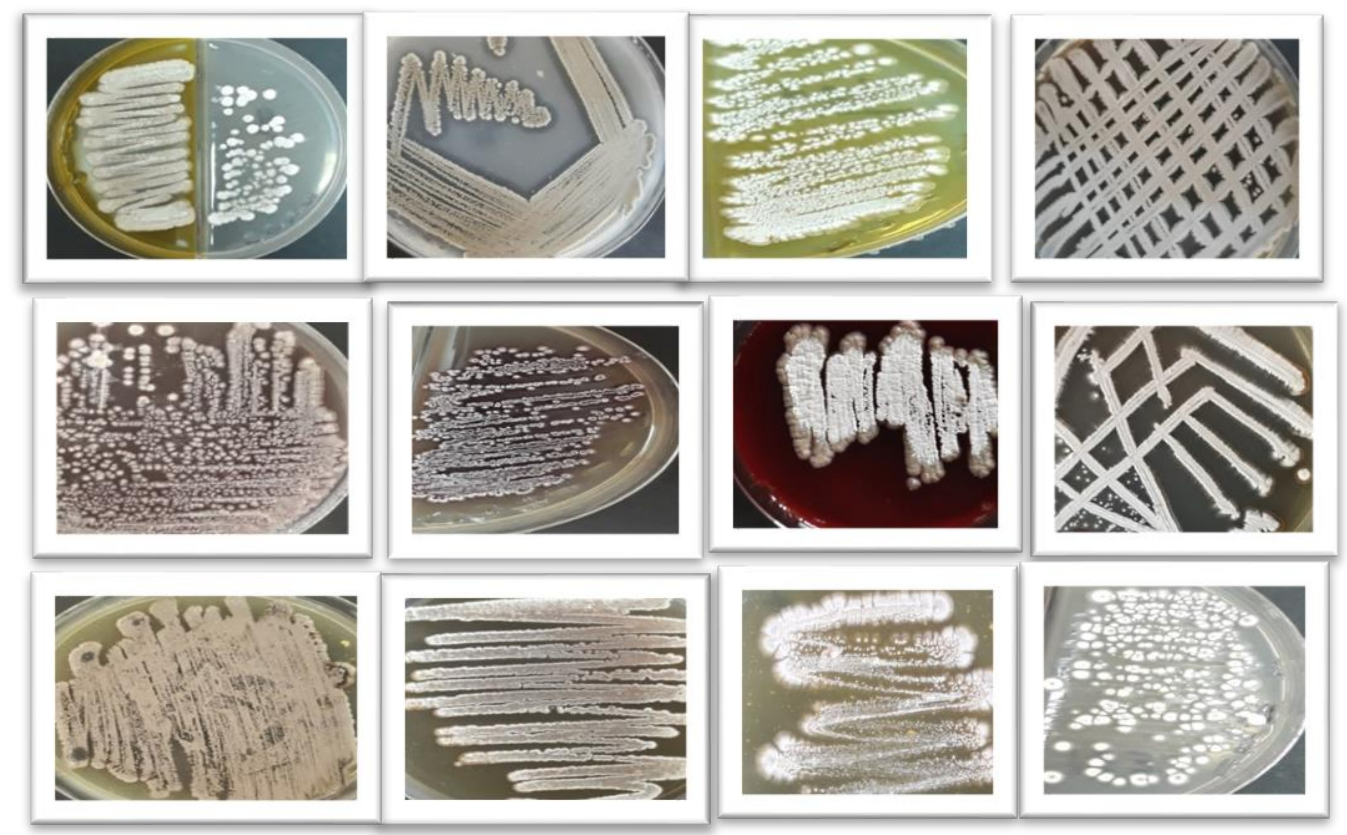

Figure 1: Morphology colonies of Streptomyces, which isolated aerial 


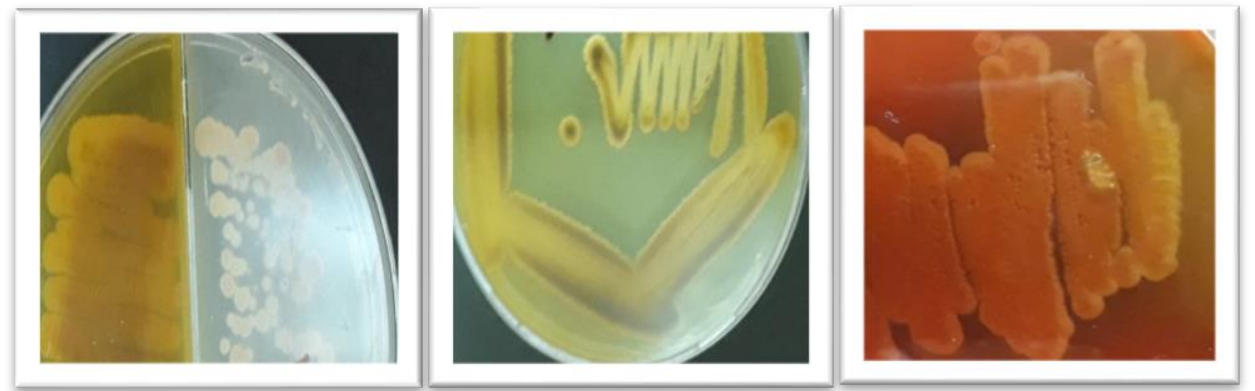

Figure 2: Streptomyces species isolated ground mycelia

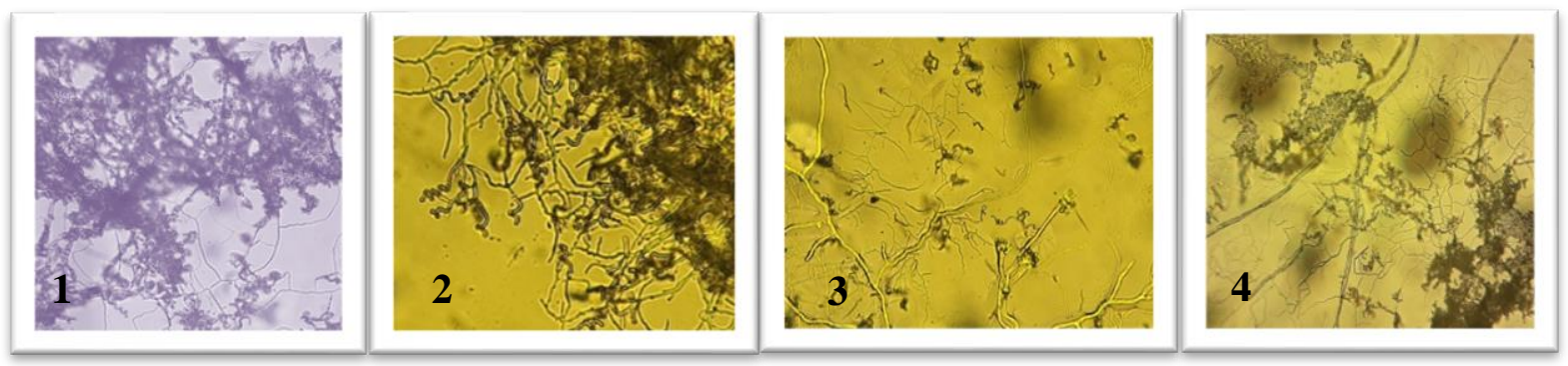

Figure 3:(1) Gram staining of isolated streptomyces under 100x magnification. (2,3,4): Glass slide technology

\section{Diagnosis}

The slide culturing method was used to diagnose Streptomyces samples, which is thought to be one of the best ways (on a genus level) to expose substrate and aerial hyphae, which are the distinguishing features that differentiate thread-like bacteria from one another. [8]

Strongly branched, unsegmented, and spore-free hyphae are present in the substrate. The threads of aerial hyphae are darker, thicker, and less branched than those of substrate hyphae. [3]. The sporophore, which can be erect (rectus), spiral (spiral), straight with a bent end (retinaculum-a cum), or straight with waves (rectus) (rectus-flexibilis), surrounds a long chain of spores in aerial hyphae [23]. When the isolates were cultured on different types of media, they displayed numerous colors, were incapable of forming melanin and other pigments, and the gray-colored colonies were the most visible (figure 1,2,3). These findings are close to those of [18].

\section{Genomic DNA polymer reaction}

Under the Geneaid procedure, a particular DNA reaction to Purified DNA was obtained from species collected from local samples.

Forward primer: [AAG CCC TGG AAA CGG GGT]

And the revers: [CGT GTG CAG CCC AAG ACA] [17][22] 


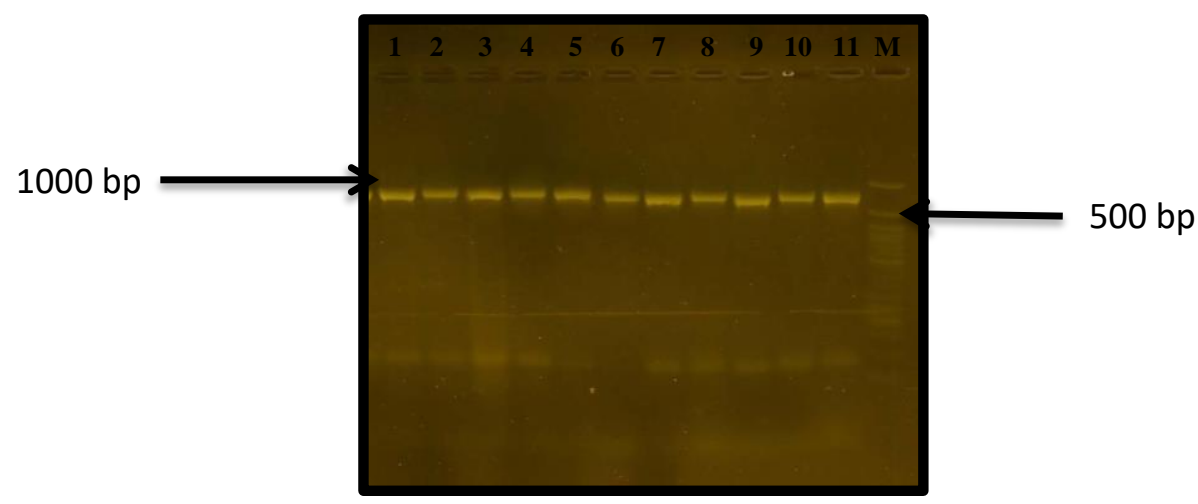

Fig.:4: The results of the bacterial samples from the region' basic polymers reaction based on primer 16s rRNA (11) Streptomyces isolates

In (Fig. 4) The samples with a similar length ( 1000 base ) pairs generated from the Streptomyces reaction DNA-specific polymer show 11 strands of purified DNA. The presence of these strands demonstrates that these isolates' genomic DNA contains shared sequences of nitrogenous bases that can join with the primer and continue the reaction, resulting in new DNA strands of the same length. These findings are similar to those of [23]. As the sequences were obtained from the nitrogenous bases of the DNA samples as follows:

Sample MU1 (Streptomyces gancidicus)

GCCCCCGCGGCCTATCAGCTTGTTGGTGAGGTAATGGCTCACCAAGGCGACGACGGGTAGC CGGCCTGAGAGGGCGACCGGCCACACTGGGACTGAGACACGGCCCAGACTCCTACGGGAG GCAGCAGTGGGGAATATTGCACAATGGGCGAAAGCCTGATGCAGCGACGCCGCGTGAGGG ATGACGGCCTTCGGGTTGTAAACCTCTTTCAGCAGGGAAGAAGCGAAAGTGACGGTACCTG CAGAAGAAGCGCCGGCTAACTACGTGCCAGCAGCCGCGGTAATACGTAGGGCGCGAGCGT TGTCCGGAATTATTGGGCGTAAAGAGCTCGTAGGCGGCTTGTCGCGTCGGTTGTGAAAGCC CGGGGCTTAACCCCGGGTCTGCAGTCGATACGGGCAGGCTAGAGTTCGGTAGGGGAGATC GCAATTCCTGGTGTAGCGGTGAAATGCGCAGATATCACGAGGACCCCCGGTGGCGAACCCG GATCTCTGGGCCGATACTG

These sequences were entered into a program DNA BLAST to show their types and how close they are to sequences in the Gene Bank, as the result of the analysis showed a similarity of (99\%) between these sequences and the sequences of bacterial isolates registered in the Gene Bank with the number (MT588801.1) Fig. (5). 


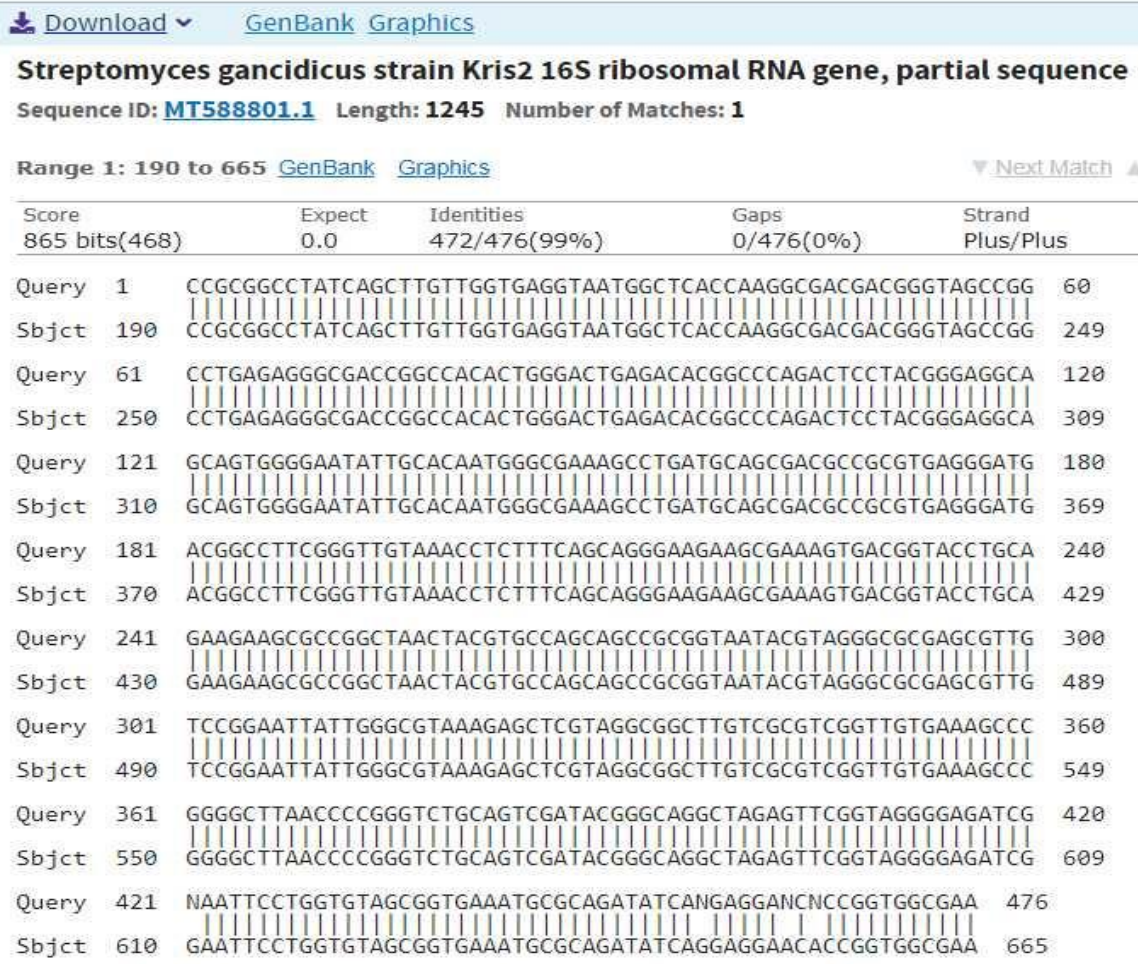

Figure: (5) Comparison of sequences of the nitrogen base between the local isolate (MU1) and standard strain (MT588801.1)

\section{Sample MU2 (Streptomyces werraensis)}

GGCGCACCCGCGGCCTATCAGCTTGTTGGTGAGGTAATGGCTCACCAAGGCGACGACGGGT AGCCGGCCTGAGAGGGCGACCGGCCACACTGGGACTGAGACACGGCCCAGACTCCTACGG GAGGCAGCAGTGGGGAATATTGCACAATGGGCGAAAGCCTGATGCAGCGACGCCGCGTGA GGGATGACGGCCTTCGGGTTGTAAACCTCTTTCAGCAGGGAAGAAGCGAAAGTGACGGTA CCTGCAGAAGAAGCGCCGGCTAACTCCCCGCCAGCAGCCGCGGTAATACGTAGGGCGCGA GCGTTCCCCCGAATTATTGGGCGTAAAGAGCTCGTAGGCGGCTTGTCGCGTCGGTTGTGAA AGCCCGGCCCTTAACCCCGGGTCTGCAGTCGATACGGGCAGGCTAGAGTTCGGTAGGGGAG ATCGGAATTCCTGGTGTAGCGGTGAAATGCGCACATATCAGGAGGAACACCGGTGGCGAA CGCGGATCTCTGGGCCGATACTGACGCTGAGGACCCAAAGCGTGGGGACCGAACAGGATC ACATCCCCTGCCACCCCCCGCCGCAAACGGCGGGCACTACGTGTGGGCGACCTTCCCCCCC CCCCCCCGCCCCCGCTACCCCCTTAACCGCCCCCCCTGGGGAGTACCGCCCCCCAGGC

The result of the program DNA BLAST analysis showed a similarity of (92\%) between sequences of bacterial isolates registered in the Gene Bank with the number (MN179978.1) Fig. (6) 
Journal of Education and Science (ISSN 1812-125X), Vol: 30, No: 3, 2021 (45-62)

Special Issue for Proceeding of $3^{\text {rd }}$ National (1st international conference of biology) (ICBSUM 2021) 5, 6 July College of Education for Pure Science, University of Mosul, Mosul, Iraq.

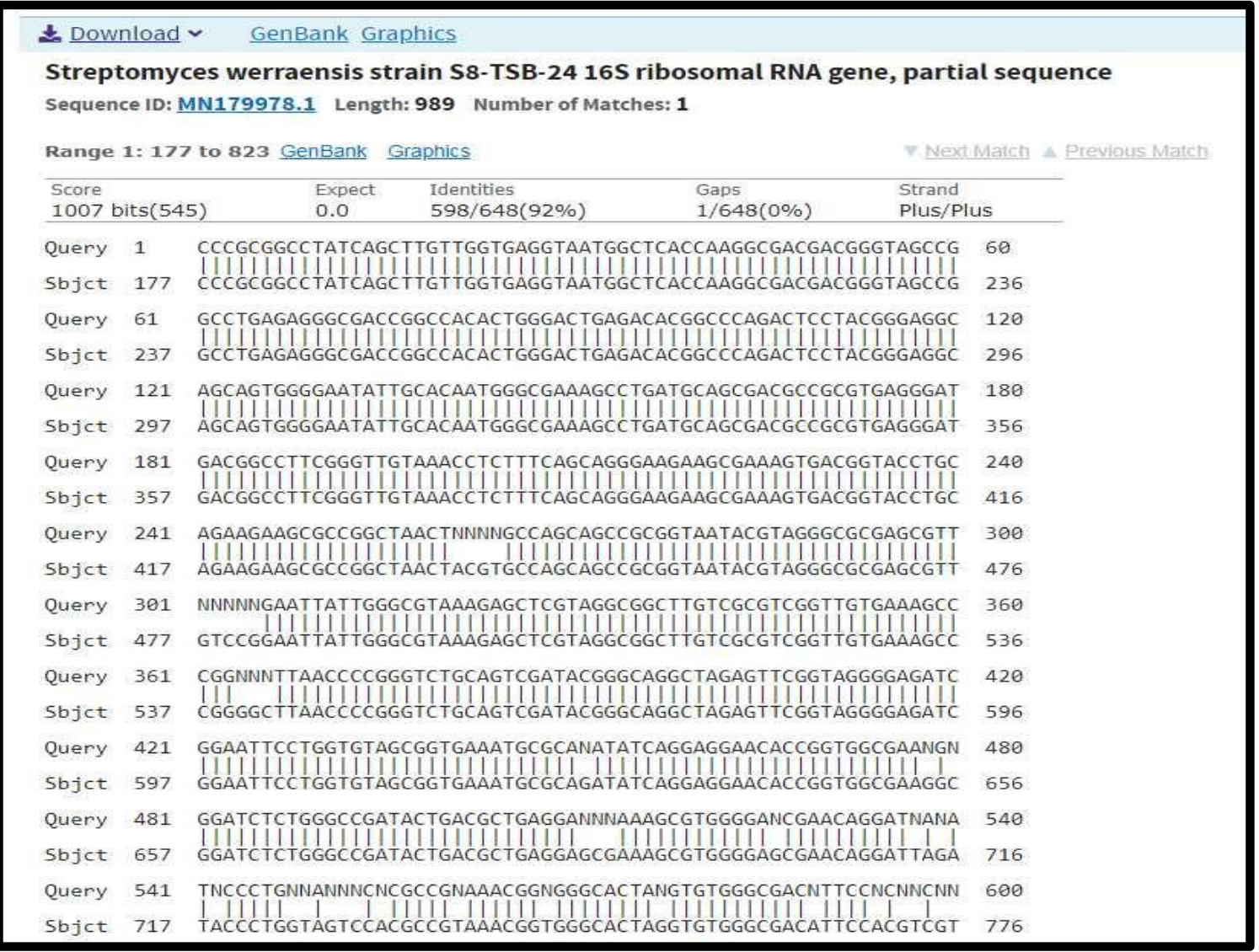

Figure: (6) Comparison of sequences the nitrogen base between the local isolate (MU2) and standard strain $\underline{\text { MN179978.1) }}$

\section{Sample MU3 (Streptomyces griseorubens)}

GTGGATGAGCCCGCGGCCTATCAGCTTGTTGGTGAGGTAATGGCTCACCAAGGCGACGACG GGTAGCCGGCCTGAGAGGGCGACCGGCCACACTGGGACTGAGACACGGCCCAGACTCCTA CGGGAGGCAGCAGTGGGGAATATTGCACAATGGGCGAAAGCCTGATGCAGCGACGCCGCG TGAGGGATGACGGCCTTCGGGTTGTAAACCTCTTTCAGCAGGGAAGAAGCGAAAGTGACG GTACCTGCAGAAGAAGCGCCGGCTAACTACGTGCCAGCAGCCGCGGTAATACGTAGGGCG CGAGCGTTGTCCGGAATTATTGGGCGTAAAGAGCTCGTAGGCGGCTTGTCACGTCGGTTGT GAAAGCCCGGGGCTTAACCCCGGGTCTGCAGTCGATACGGGCAGGCTAGAGTTCGGTAGG GGAGATCGGAATTCCTGGTGTAGCGGTGAAATGCGCAGATATCAGGAGGAACACCGGTGG CGAAGGCGGATCTCTGGGCCGATACTGACGCTGAGGAGCGAAAGCGTGGGGAGCGAACAG GATTAGATACCCTGGTAGTCCACGCCGTAAACGGTGGGCACTAGGTGTGGGCGACATTCCA CGTCGTCCGTGCCGCAGCTAACGCATTAAGTGCCCCGCCTGGGGAGTACGGCCGCAAGGCT AAAACTCAAAGGATTTGACGGGGGCCCGCACAAGCGGCGGAGCATGTGGCTTAATTCGAC GCAACGCGAAGAACCTTACCACGGCTTGACATACACCGGAAAGAGGCCCCCTTGCCGCCG GCGACCGGCGCCCATCGGTCAGCTCCCGTCGCGAGCCGCTGGGTTAAGTCCGCAACCAGCG CACCCTTG

The result of the program DNA BLAST analysis showed a similarity of (99\%) between sequences of bacterial isolates registered in the Gene Bank with the number (MT525003.1) Fig. (7) 


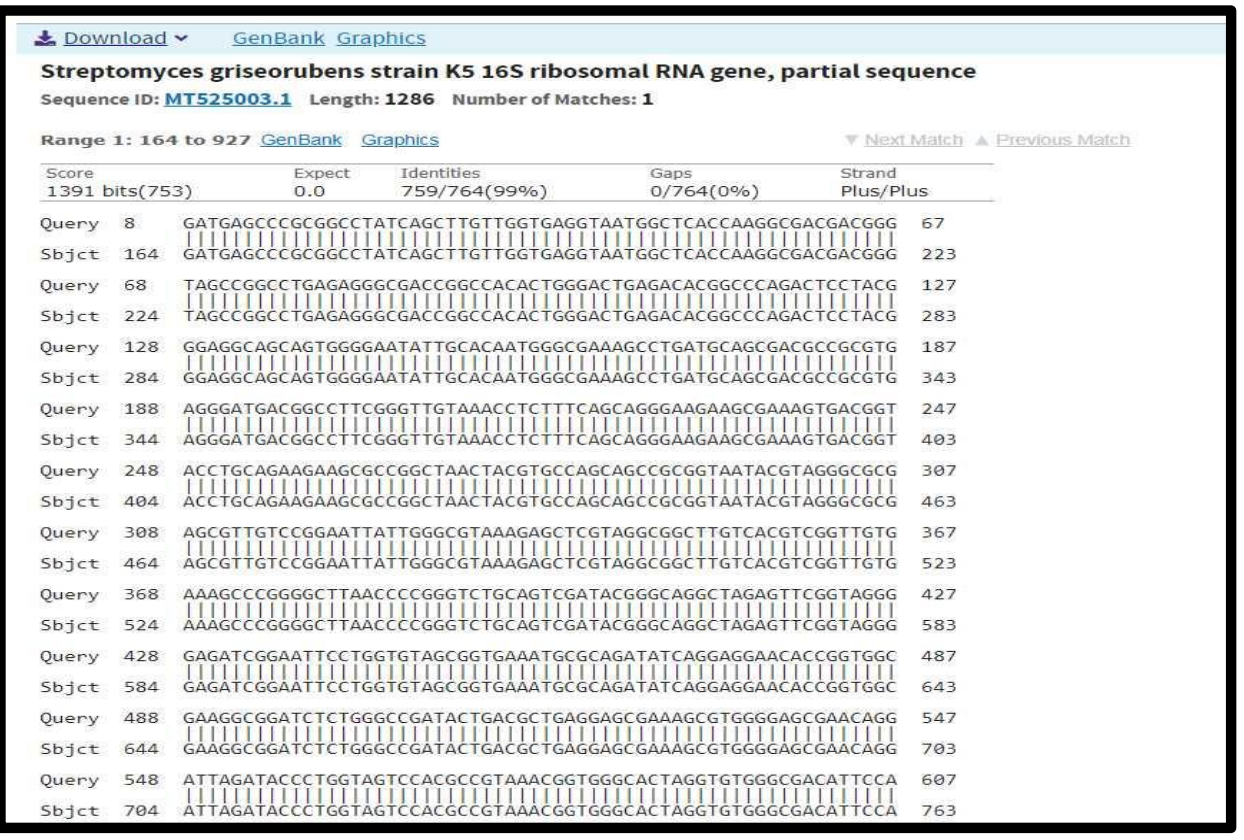

Figure: (7) Comparison of sequences the nitrogen base between the local isolate (MU3) and standard strain (MT525003.1)

Sample MU4 (Streptomyces hawaiiensis)

GGCGGTGCAGGATGAGCCCGCGGCCTATCAGCTTGTTGGTGAGGTAGTGGCTCACCAAGGC GACGACGGGTAGCCGGCCTGAGAGGGCGACCGGCCACACTGGGACTGAGACACGGCCCAG ACTCCTACGGGAGGCAGCAGTGGGGAATATTGCACAATGGGCGAAAGCCTGATGCAGCGA CGCCGCGTGAGGGATGACGGCCTTCGGGTTGTAAACCTCTTTCAGCAGGGAAGAAGCGAA AGTGACGGTACCTGCAGAAGAAGCGCCGGCTAACTACGTGCCAGCAGCCGCGGTAATACG TAGGGCGCGAGCGTTGTCCGGAATTATTGGGCGTAAAGAGCTCGTAGGCGGCTTGTCACGT CGGTTGTGAAAGCCCGGGGCTTAACCCCGGGTCTGCAGTCGATACGGGCAGGCTAGAGTTC GGTAGGGGAGATCGGAATTCCTGGTGTAGCGGTGAAATGCGCAGATATCAGGAGGAACAC CGGTGGCGAAGGCGGATCTCTGGGCCGATAC

The result of the program DNA BLAST analysis showed a similarity of $(91 \%)$ between sequences of bacterial isolates registered in the Gene Bank with the number (MT36169.1) Fig. (8)

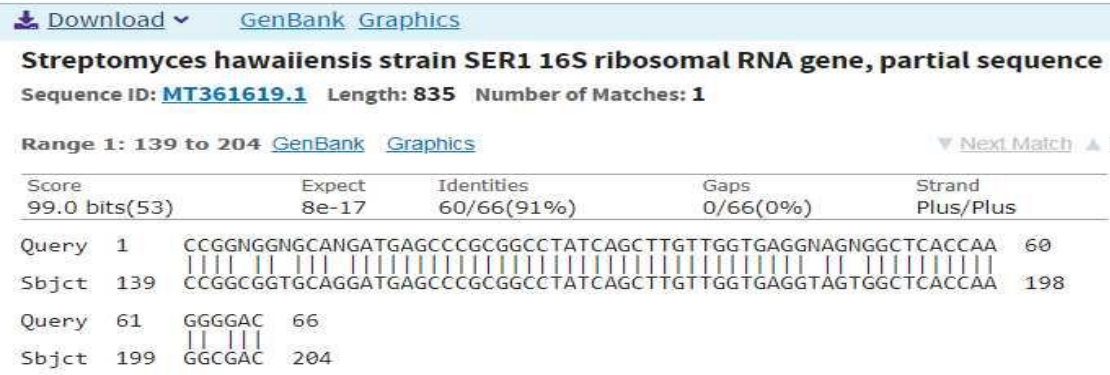

Figure: (8) Comparison of sequences the nitrogen base between the local isolate (MU4) and standard strain $\underline{\text { MT36169.1) }}$ 
Journal of Education and Science (ISSN 1812-125X), Vol: 30, No: 3, 2021 (45-62)

Special Issue for Proceeding of $3^{\text {rd }}$ National (1 ${ }^{\text {st }}$ international conference of biology) (ICBSUM 2021) 5, 6 July College of Education for Pure Science, University of Mosul, Mosul, Iraq.

\section{Sample MU5 (Streptomyces thermocarboxydus)}

CCCGCGGCCTATCAGCTTGTTGGTGAGGTAATGGCTCACCAAGGCGACGACGGGTAGCCGG CCTGAGAGGGCGACCGGCCACACTGGGACTGAGACACGGCCCAGACTCCTACGGGAGGCA GCAGTGGGGAATATTGCACAATGGGCGAAAGCCTGATGCAGCGACGCCGCGTGAGGGATG ACGGCCTTCGGGTTGTAAACCTCTTTCAGCAGGGAAGAAGCGAAAGTGACGGTACCTGCAG AAGAAGCGCCGGCTAACTACGTGCCAGCAGCCGCGGTAATACGCACGGCGCGAGCGTTGT CCGGAATTATTGGGCGTAAAGAGCTCGTAGGCGGCTTGTCCCGTCGGTTGTGAAAGCCCGG GGCTTAACCCCGGGTCTGCAGTCGATACGGCCAGGCTAGAGTTCGGTAGGGGAGATCGGAC TTCCTGGTGTAGCGGCGAAATGCCCCCATATCACGAGGACCCCCCGGTGGCGAAAGCGGAT CTCTGGGGCCGATACTGACGCTGAGGAGCGAAAGCGTGGGGAGCGAACAGGATTACATAC CCCTGGAGCCCCCCCGCCCACGGTGGGCCCTACGT

The result of the program DNA BLAST analysis showed a similarity of (96\%) between sequences of bacterial isolates registered in the Gene Bank with the number (KU158245.1) Fig. (9)

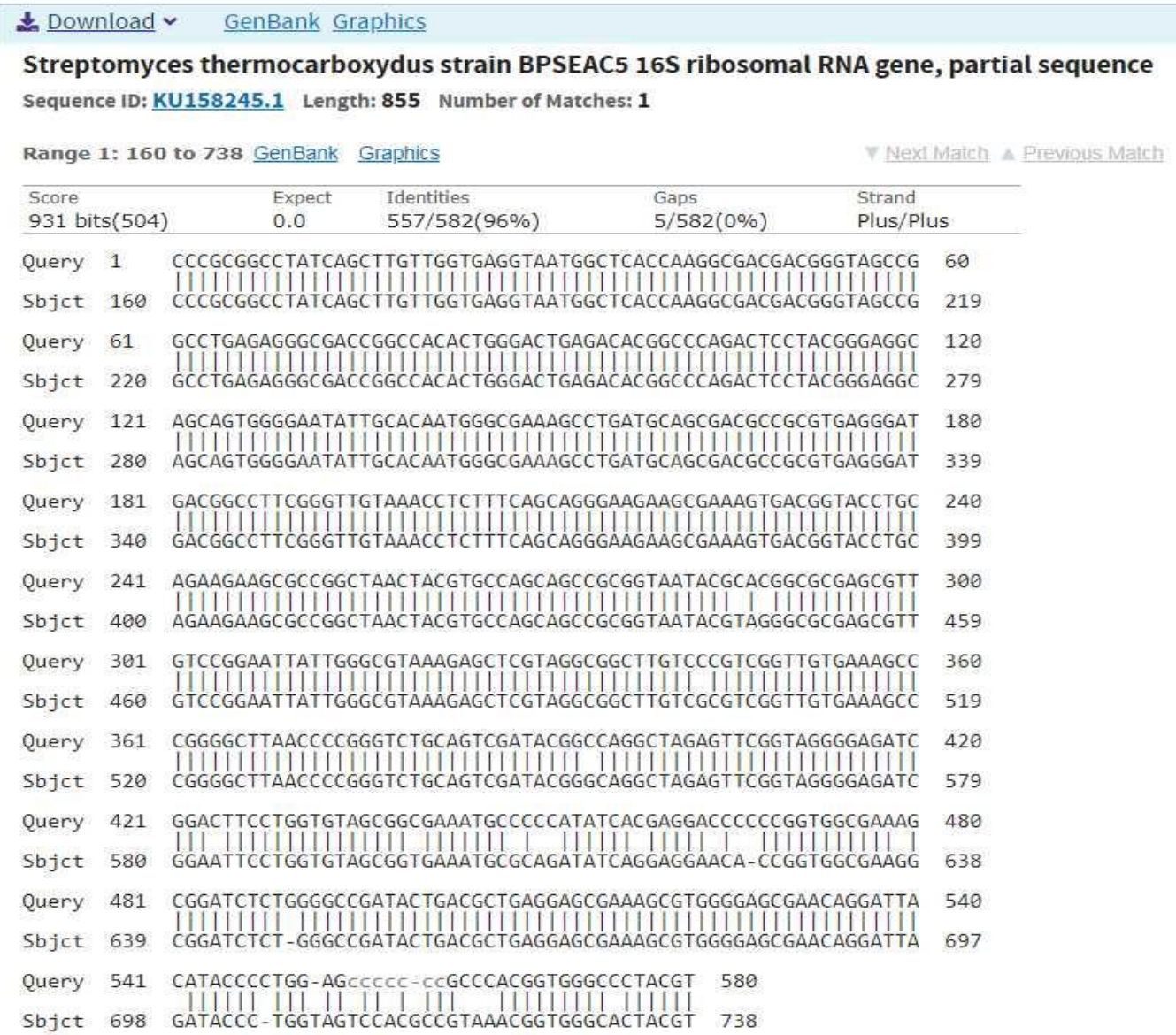

Figure: (9) Comparison of sequences the nitrogen base between the local isolate (MU5) and standard strain (KU158245.1) 
Journal of Education and Science (ISSN 1812-125X), Vol: 30, No: 3, 2021 (45-62)

Special Issue for Proceeding of $3^{\text {rd }}$ National (1 ${ }^{\text {st }}$ international conference of biology) (ICBSUM 2021) 5, 6 July College of Education for Pure Science, University of Mosul, Mosul, Iraq.

\section{Sample MU6 (Streptomyces cyaneus)}

CCTCCTTCGGGAGGGGATTAGTGGCGAACGGGTGAGTAACACGTGGGCAATCTGCCCTGCA CTCTGGGACAAGCCCTGGAAACGGGGTCTAATACCGGATACTGATCATCTTGGGCATCCTT GGTGATCGAAAGCTCCGGCGGTGCAGGATGAGCCCGCGGCCTATCAGCTTGTTGGTGAGGT AATGGCTCACCAAGGCGACGACGGGTAGCCGGCCTGAGAGGGCGACCGGCCACACTGGGA CTGAGACACGGCCCAGACTCCTACGGGAGGCAGCAGTGGGGAATATTGCACAATGGGCGA AAGCCTGATGCAGCGACGCCGCGTGAGGGATGACGGCCTTCGGGTTGTAAACCTCTTTCAG CAGGGAAGAAGCGAAAGTGACGGTACCTGCAGAAGAAGCGCCGGCTAACTACGTGCCAGC AGCCGCGGTAATACGTAGGGCGCGAGCGTTGTCCGGAATTATTGGGCGTAAAGAGCTCGTA GGCGGCTTGTCGCGTCGGTTGTGAAAGCCCGGGGCTTAACCCCGGGTCTGCAGTCGATACG GGCAGGCTAGAGTTCGGTAGGGGAGATCGGAATTCCTGGTGTAGCGGTGAAATGCGCAGA TATCACGAGGAACACCGGTGGCGAAAGCGGATCTCTGGGCCGATACTGACGCTGAGGAGC GAAAGCGTGGGGAGCGAACAGGATTAGATACCCTGGTAGTCCACGCCGTAAACGGTGGGC ACTAGGTGTGGGCGACATTCCACGTCGTCCGTGCCGCAGCTAACGCATTAAGTGCCCCGCC TGGGGGAGTACGGCCGCAAGGCTAAAACTCAAA

The result of the program DNA BLAST analysis showed a similarity of (99\%) between sequences of bacterial isolates registered in the Gene Bank with the number (KM215731.1) Fig. (10)

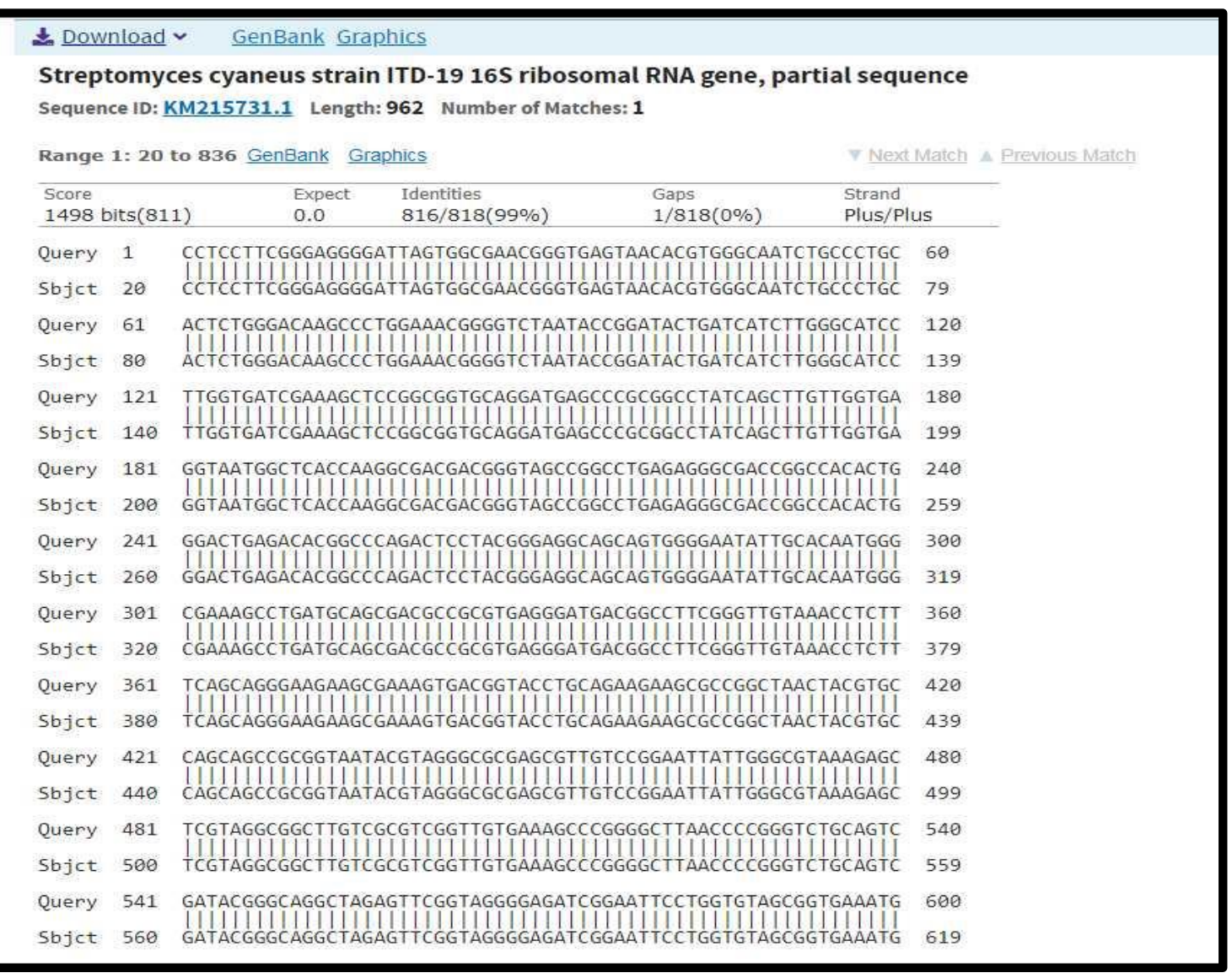

Figure: (10) Comparison of sequences the nitrogen base between the local isolate (MU6) and standard strain ( $\underline{\text { KM215731.1) }}$ 
Journal of Education and Science (ISSN 1812-125X), Vol: 30, No: 3, 2021 (45-62)

Special Issue for Proceeding of $3^{\text {rd }}$ National (1 ${ }^{\text {st }}$ international conference of biology) (ICBSUM 2021) 5, 6 July College of Education for Pure Science, University of Mosul, Mosul, Iraq.

\section{Sample MU7 (Streptomyces misionensis)}

AGCCCGCGGCCTATCAGCTTGTTGGTGAGGTAATGGCTCACCAAGGCGACGACGGGTAGCC GGCCTGAGAGGGCGACCGGCCACACTGGGACTGAGACACGGCCCAGACTCCTACGGGAGG CAGCAGTGGGGAATATTGCACAATGGGCGAAAGCCTGATGCAGCGACGCCGCGTGAGGGA TGACGGCCTTCGGGTTGTAAACCTCTTTCAGCAGGGAAGAAGCGAAAGTGACGGTACCTGC AGAAGAAGCGCCGGCTAACTACGTGCCAGCAGCCGCGGTAATACGTAGGGCGCGAGCGTT GTCCGGAATTATTGGGCGTAAAGAGCTCGTAGGCGGCTTGTCACGTCGGTTGTGAAAGCCC GGGGCTTAACCCCGGGTCTGCAGTCGATACGGGCAGGCTAGAGTTCGGTAGGGGAGATCG GAATTCCTGGTGTAGCGGTGAAATGCGCAGATATCAGGAGGAACACCGGTGGCGAAGGCG GATCTCTGGGCCGATACTGACGCTGAGGAGCGAAACCCTGGGGAGCGAACAGGATTACAT ACCCTGGTACTCCACGCCGTACACGGTGGGCACTAGGTGTGGGCAACATTCCACGTTGTCC GTGCCGCAGCTAACGCATTAAGTGCCCCGCCTGGGGAGTACGGCCGCAAGGCTCACACTCC AAGGACTCGACCGGGGCCCCCACAAGCGGCGGACCATGCGGCTTACTCCCACCCCCCGCCA AAAC

The result of the program DNA BLAST analysis showed a similarity of (97\%) between sequences of bacterial isolates registered in the Gene Bank with the number (MT515826.1 ) Fig. (11)

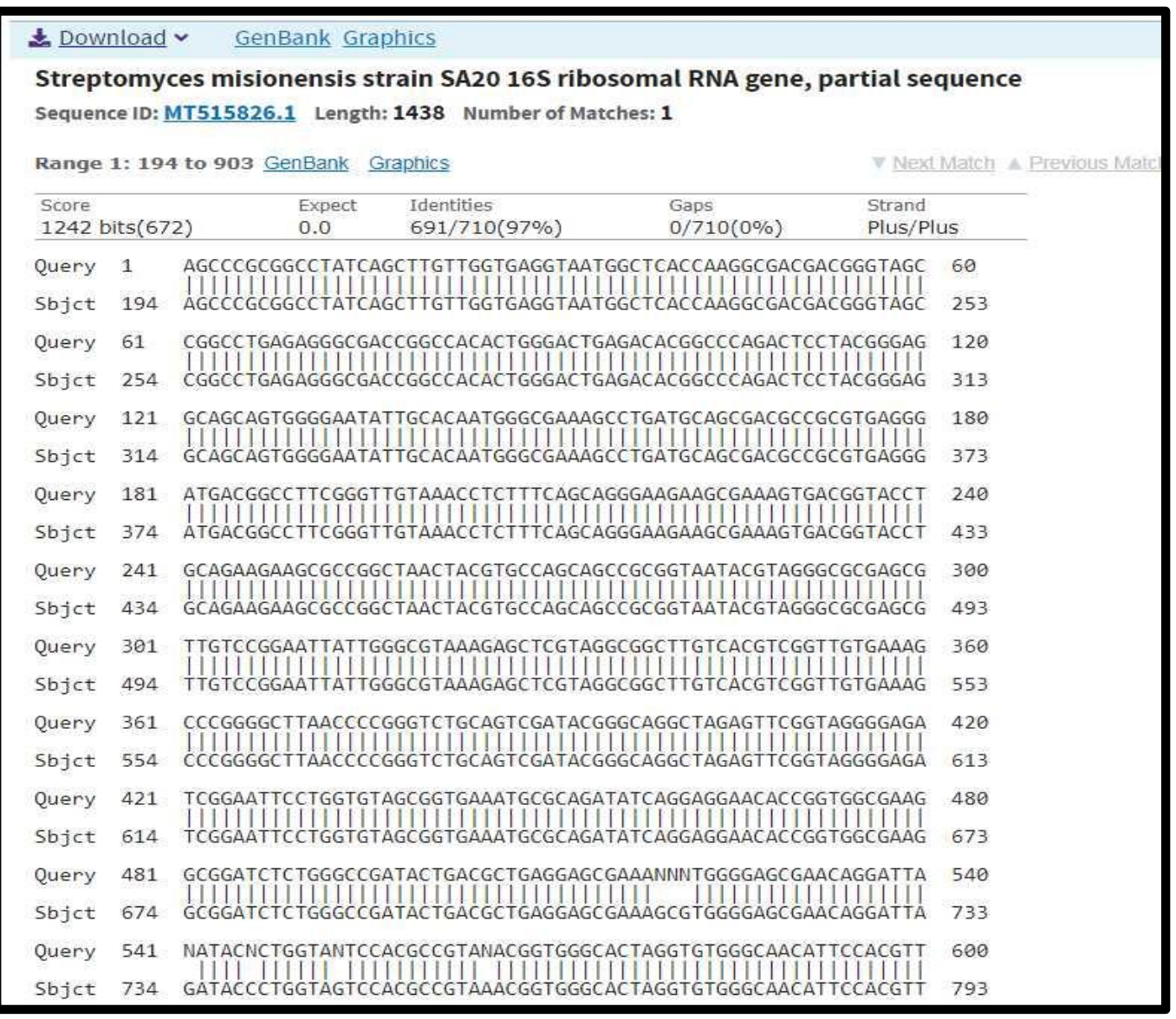

Figure: (11) Comparion of sequences the nitrogen base between the local isolate (MU7) and standard strain (MT515826.1 
Journal of Education and Science (ISSN 1812-125X), Vol: 30, No: 3, 2021 (45-62)

Special Issue for Proceeding of $3^{\text {rd }}$ National (1 ${ }^{\text {st }}$ international conference of biology) (ICBSUM 2021) 5, 6 July College of Education for Pure Science, University of Mosul, Mosul, Iraq.

\section{Sample MU8 ( Streptomyces bellus )}

AGTTTGATCATGGCTCAGGACGAACGCTGGCGGCGTGCTTAACACATGCAAGTCGAACGAT GAACCACTTCGGTGGGGATTAGTGGCGAACGGGTGAGTAACACGTGGGCAATCTGCCCTGC ACTCTGGGACAAGCCCTGGAAACGGGGTCTAATACCGGATACTGACCCGCTTGGGCATCCA AGCGGTTCGAAAGCTCCGGCGGTGCAGGATGAGCCCGCGGCCTATCAGCTTGTTGGTGAGG TAATGGCTCACCAAGGCGACGACGGGTAGCCGGCCTGAGAGGGCGACCGGCCACACTGGG ACTGAGACACGGCCCAGACTCCTACGGGAGGCAGCAGTGGGGAATATTGCACAATGGGCG AAAGCCTGATGCAGCGACGCCGCGTGAGGGATGACGGCCTTCGGGTTGTAAACCTCTTTCA GCAGGGAAGAAGCGAAAGTGACGGTACCTGCAGAAGAAGCGCCGGCTAACTACGTGCCAG CAGCCGCGGTAATACGTAGGGCGCGAGCGTTGTCCGGAATTATTGGGCGTAAAGAGCTCGT AGGCGGCTTGTCACGTCGGTTGTGAAAGCCCGGGGCTTAACCCCGGGTCTGCAGTCGATAC GGGCAGGCTAGAGTTCGGTAGGGGAGATCGGAATTCCTGGTGTAGCGGTGAAATGCGCAG ATATCAGGAGGAACACCGGTGGCGAAAGCGGATCTCTGGGCCGATACTGACGCTGAGGAG CGAAAGCGTGGGGAGCGAACAGGATTAGATACCCTGGTAGTCCACGCCGTAAACGGTGGG CACTAGGTGTGGGCGACATTC

The result of the program DNA BLAST analysis showed a similarity of (99\%) between sequences of bacterial isolates registered in the Gene Bank with the number (MT355856.1) Fig. (12)

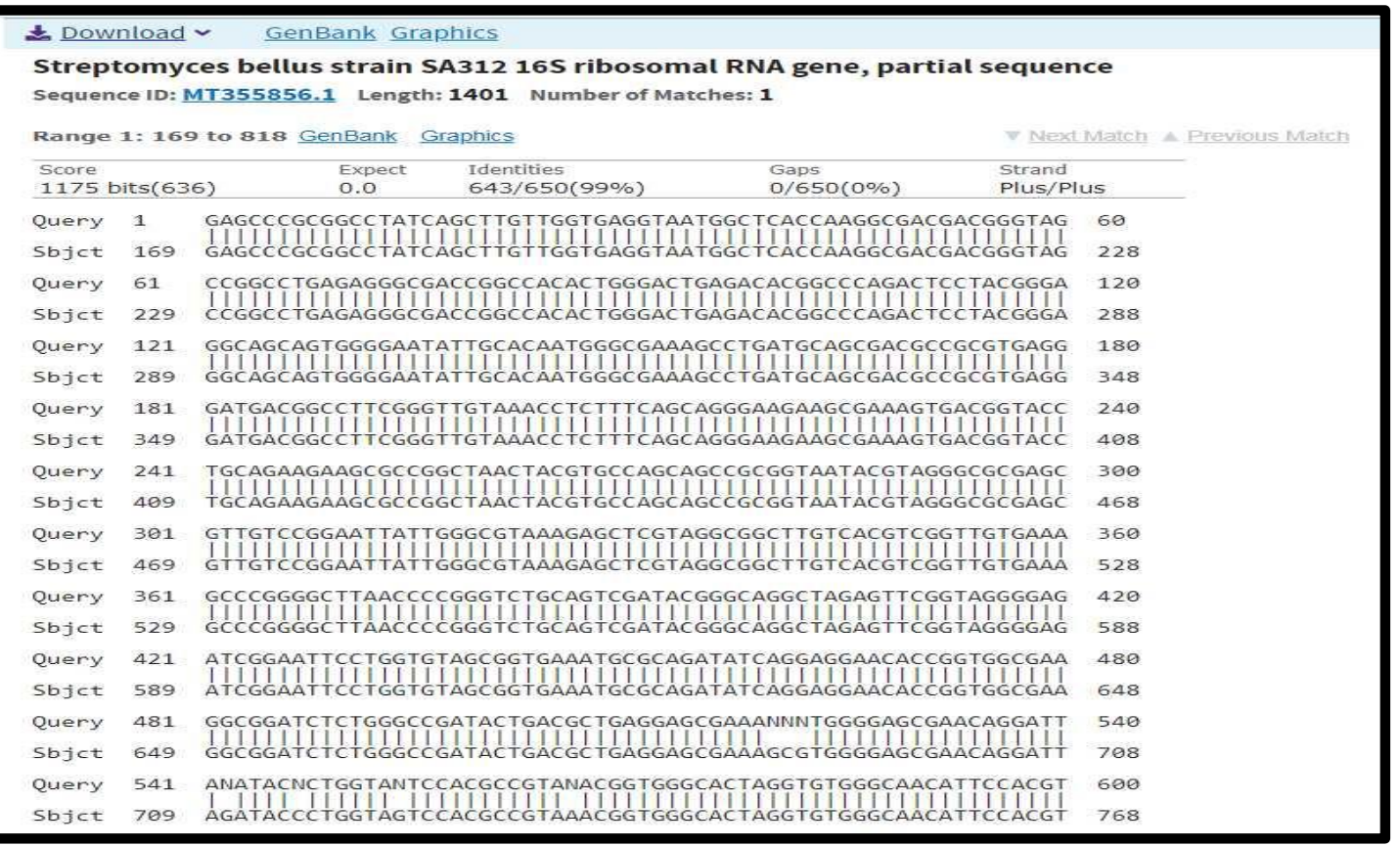

Figure: (12) Comparison of sequences the nitrogen base between the local isolate (MU8) and standard strain $\underline{(\text { MT515826.1) }}$

Sample MU9 (Streptomyces parvulus)

GCGCCCCCCGCCTATCCCCTTGTTGGTGAGGCAATGGCTCACCAAGGCGACGACGGGTAGC CGGCCTGAGAGGGCGACCGGCCACCCTGGGACTGAGACACGGCCCAGACTCCTACGGGAG GCAGCAGTGGGGAATATTGCACAATGGGCGAAAGCCTGATGCAGCGACGCCGCGTGAGGG 
Journal of Education and Science (ISSN 1812-125X), Vol: 30, No: 3, 2021 (45-62)

Special Issue for Proceeding of $3^{\text {rd }}$ National (1 ${ }^{\text {st }}$ international conference of biology) (ICBSUM 2021) 5, 6 July College of Education for Pure Science, University of Mosul, Mosul, Iraq.

ATGACGGCCTTCGGGTTGTAAACCTCTTTCCCCACGGAAGAAGCGAAAGTGACGGCACCTG CAGAAGAAGCGCCCCCTAACTACGTGCCAGCAGCCGCGGTAATACGTAGGGCGCGAGCGT TGCCCCCAATTATTGGGCGTAAAGAGCTCCTAGGCGGCTTGTCCCGTCGGCTGTGAAAGCC CGGCGCTTACCCCCCCCCCCCCCCCCCCCCTACCCCCCCC

The result of the program DNA BLAST analysis showed a similarity of (93\%) between sequences of bacterial isolates registered in the Gene Bank with the number (JX860396.1) Fig. (13)

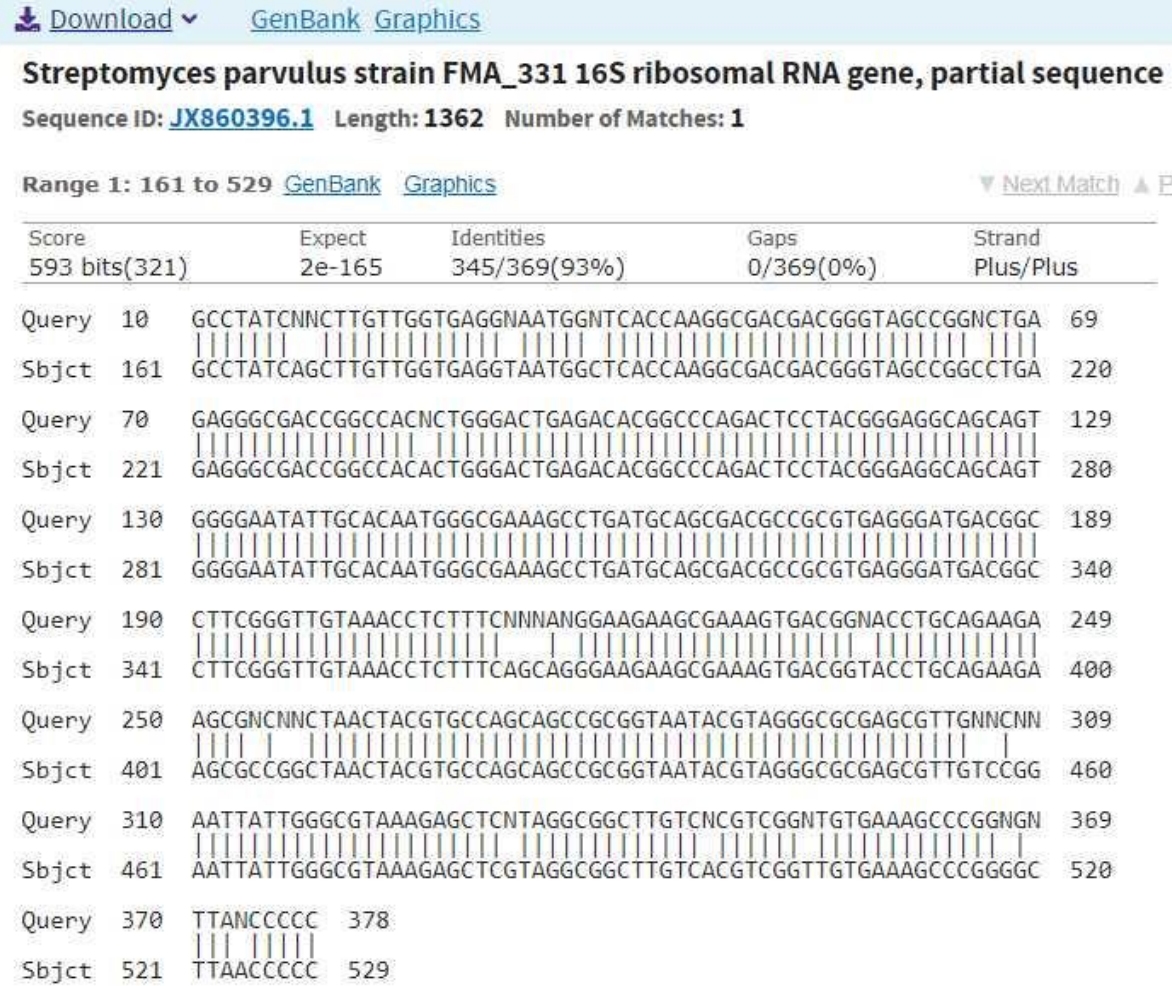

Figure: (13) Comparison of sequences the nitrogen base between the local isolate (MU9) and standard strain ( $\underline{\mathbf{J X 8 6 0 3 9 6 . 1}}$

\section{Sample MU10 (Streptomyces labedae)}

GAGCCCGCGGCCTATCAGCTTGTTGGTGAGGTAATGGCTCACCAAGGCGACGACGGGTAGC CGGCCTGAGAGGGCGACCGGCCACACTGGGACTGAGACACGGCCCAGACTCCTACGGGAG GCAGCAGTGGGGAATATTGCACAATGGGCGAAAGCCTGATGCAGCGACGCCGCGTGAGGG ATGACGGCCTTCGGGTTGTAAACCTCTTTCAGCAGGGAAGAAGCGAAAGTGACGGTACCTG CAGAAGAAGCGCCGGCTAACTACGTGCCAGCAGCCGCGGTAATACGTAGGGCGCGAGCGT TGTCCGGAATTATTGGGCGTAAAGAGCTCGTAGGCGGCTTGTCACGTCGGTTGTGAAAGCC CGGGGCTTAACCCCGGGTCTGCAGTCGATACGGGCAGGCTAGAGTTCGGTAGGGGAGATC GGAATTCCTGGTGTAGCGGTGAAATGCGCAGATATCAGGAGGAACACCGGTGGCGAAGGC GGATCTCTGGGCCGATACTGACGCTGACGAGCGAAAGCGTGGGGAGCGAACAGGATTAGA TACCCTGGTAGTCCACGCCGCAAACGGTGGGCACTCCCGTGGGCGACCCCCCCCGTCGCCC 
Journal of Education and Science (ISSN 1812-125X), Vol: 30, No: 3, 2021 (45-62)

Special Issue for Proceeding of $3^{\text {rd }}$ National (1 ${ }^{\text {st }}$ international conference of biology) (ICBSUM 2021) 5, 6 July

College of Education for Pure Science, University of Mosul, Mosul, Iraq.

CGTGCCGCAGCTAACGCATTAAGTGCCCCGCCTGGGGAGTACGGCCGCAAGGCTAAAACTC ACAGGAATTGACGGGGGCCCCGCCCCACCCGCCGGACCCTGTGGCTTATTCACGCACACTC CGCT

The result of the program DNA BLAST analysis showed a similarity of (96\%) between sequences of bacterial isolates registered in the Gene Bank with the number (JQ647891.1) Fig. (14)

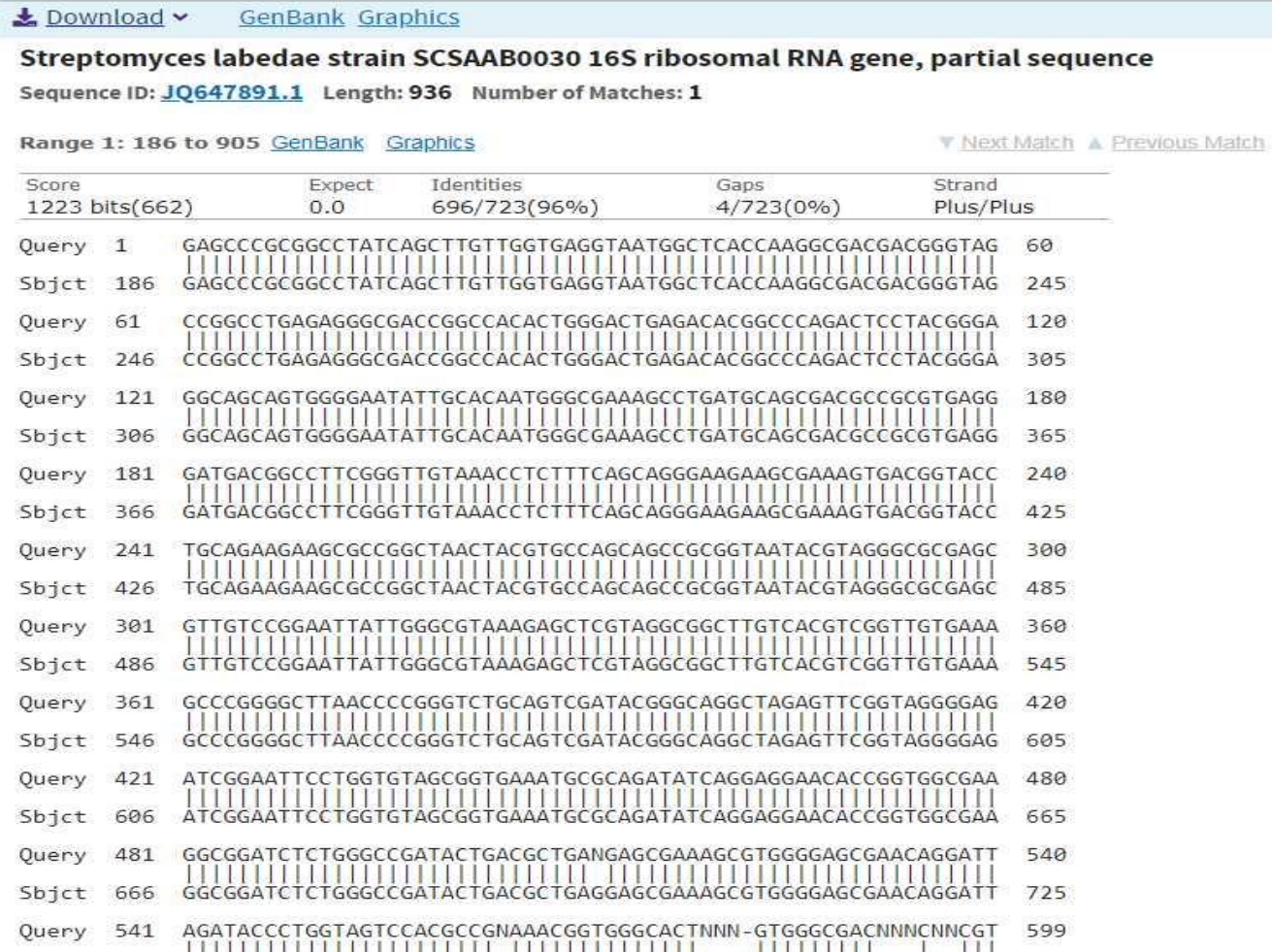

Figure: (14) Comparison of sequences the nitrogen base between the local isolate (MU10) and standard strain $(\underline{\text { JQ647891.1) }}$

Sample MU11 (Streptomyces variabilis)

GGCGCACGACGAGCCCGCGGCCTATCAGCTTGTTGGTGAGGTAATGGCTCCCCAAGGCGAC GACGGGTAGCCGGCCTGAGAGGGCGACCGGCCACACTGGGACTGAGACACGGCCCAGACT CCTACGGGAGGCAGCAGTGGGGAATATTGCACAATGGGCGAAAGCCTGATGCAGCGACGC CGCGTGAGGGATGACGGCCTTCGGGTTGTAAACCTCTTTCAGCAGGGAAGAAGCGAAAGT GACGGTACCTGCAGAAGAAGCGCCGGCTAACTACGTGCCAGCAGCCGCGGTAATACGTAG GGCGCGAGCGTTGTCCGGAATTATTGGGCGTAAAGAGCTCGTAGGCGGCTTGTCGCGTCGG TTGTGAAAGCCCGGGGCTTAACCCCGGGTCTGCAGTCGATACGGGCAGGCTACCAGTTCGG TAGGGGAGATCGGAATTCCTGGTGTACCGGTGAAATGCGCAGATATCCCGAGGAACACCC GGTGGCGAAGGCGGATCTCTGGGCCCGATACTGACGCTGAGGACCGAAAGCGTGGGGAGC $\mathrm{C}$

The result of the program DNA BLAST analysis showed a similarity of (97\%) between sequences of bacterial isolates registered in the Gene Bank with the number (EU841660.1) Fig. (15) 


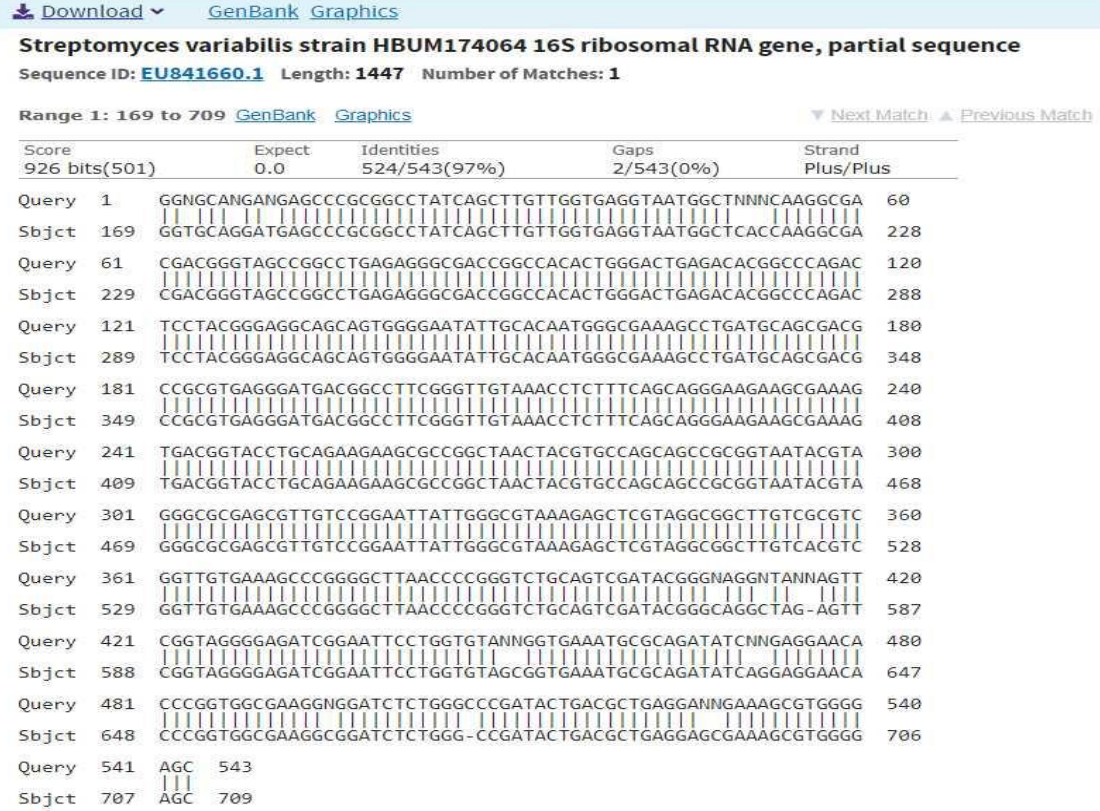

Figure: (15) Comparison of sequences the nitrogen base between the local isolate (MU11) and standard strain (EU841660.1)

The partial 16S rRNA sequences deposited in GenBank were analyzed using DNA Blast (Figure $5,6,7,8,9,10,11,12,13,14,15)$. It was discovered in that all isolates belong to a Streptomyces species with (77-99\%) resemblance to the 16S rRNA series of closely related species. 16S rRNA, bacterial genetic maker often In chromosomal DNA, there is a multigene family or operons. The role of this gene has changed dramatically over time, and its size is now large enough for informatics purposes. [24].

\section{References}

[1] S. I. Al-Obaidi. Isolation of Different Local Species of the Genus Streptomyces and Study of their Antimicrobial Activity Identification by Biochemical Tests and Obtaining of Genetic Variation of Isolates by PCR RAPD Technique. Ph.D. Thesis, College of Education, University of Mosul. Mosul, Iraq. (2012).

[2] M.T. Madigan, J.M. Martinko, and J. parker. Brock, Biology of microorganisms. 10th ed. Pearson Education, Inc. prentice Hall. U.S.A., pp. 621-729 (2003).

[3] S. Azimi, M. Basei Salehi and N. Bahador. Isolation and Identification of Streptomyces ramulosus from Soil and Determination of Antimicrobial Property of its Pigment. Modern Medical Laboratory Journal, vol 1 no.(1), pp. 36-41. (2017).

[4] L.A. Al_Husnan, and M.D. Alkahtani. Molecular Identification of Streptomyces producing antibiotics and their antimicrobial activities. Annals of Agricultural Sciences, vol 61 no.(2) pp. 251-255. (2016). 
Journal of Education and Science (ISSN 1812-125X), Vol: 30, No: 3, 2021 (45-62)

Special Issue for Proceeding of $3^{\text {rd }}$ National (1 ${ }^{\text {st }}$ international conference of biology) (ICBSUM 2021) 5, 6 July

College of Education for Pure Science, University of Mosul, Mosul, Iraq.

[5] K. Khadayat, D. D. Sherpa, K. P. Malla, S. Shrestha, N. Rana, B. P. Marasini, \& N. Parajuli, Molecular Identification and Antimicrobial Potential of Streptomyces Species from Nepalese Soil. International journal of microbiology, (2020).

[6] K. Poole, Mechanisms of bacterial biocide and antibiotic resistance. Journal of applied microbiology, 92, 55S-64S. (2002).

[7] M. Masand, K. K. Sivakala, E. Menghani, T. Thinesh, R. Anandham, G, Sharma, \& P. A. Jose, Biosynthetic potential of bioactive Streptomycetes isolated from arid region of the Thar desert, Rajasthan (India). Frontiers in microbiology, 9, 687. (2018).

[8] H. F. Hussien, \& S. I. Al-Obaidi. Molecular And Biochemical Diagnosis Of Local Isolates Of Streptomyces Species From Soils Of Iraq. Plant Archives, vol 21 no(1),pp 1408-1418. (2021).

[9] O. Ceylan, G. Okmen, \& A. Ugur. Isolation of soil Streptomyces as source antibiotics active against antibiotic-resistant bacteria. EurAsian Journal of BioSciences, vol 2 no.(1) pp. 73-82. (2008).

[10] W. B. Whitman, M. Goodfellow, P. Kämpfer, H. J. Busse, M. E. Trujillo, W. Ludwig, \& K. I. Suzuki. (Eds.). Bergey's manual of systematic bacteriology: Volume 5: The Actinobacteria. Springer New York. (2012).

[11] S. J. Naine, C. S. Devi, \& V. Mohanasrinivasan, Antimicrobial, Antioxidant and Cytotoxic Activity of MarineStreptomyces parvulus VITJS11 Crude Extract. Brazilian Archives of Biology and Technology, vol 58 no.(2),pp 198-207. (2015).

[12] A. I. Khattab, H. E . Babiker, \& H. A. Saeed. Streptomyces Species From Red Sea Habitat: Isolation, Characterization And Screening For Antibacterial Compounds. International Journal Of Pharmaceutical, Chemical \& Biological Sciences, 6(1). (2016).

[13] J. E. Kang, J. W Han, B. J. Jeon, \& B. S. Kim. Efficacies of quorum sensing inhibitors, piericidin A and glucopiericidin A, produced by Streptomyces xanthocidicus KPP01532 for the control of potato soft rot caused by Erwinia carotovora subsp. atroseptica. Microbiological research, pp 184, 32-41. (2016).

[14] S. J. Wani, \& R. Z. Sayyed. Production, efficient recovery and partial characterization of biodegradable polymer produced by soil Streptomyces sp (2016).

[15] T. M. Nguyen, \& J. Kim. Antifungal and antibacterial activities of Streptomyces polymachus sp. nov. isolated from soil. International Journal of Systematic and evolutionary microbiology, vol 65 no.(8),pp 2385-2390. (2015).

[17] M. A. DePristo, E. Banks, R. Poplin, K. V. Garimella, J. R. Maguire, C. Hartl, A.A. Philippakis, G. Del Angel, M.A. Rivas, M. Hanna, and A. McKenna. A framework for variation discovery and genotyping using next-generation DNA sequencing data. Nature genetics, vol 43 no.(5), pp 491. (2011).

[18] M. B. I. Kassim, \& S. S. Eleya. Investigation of the Antimicrobial Activity of Some Streptomyces spp. Isolated from Nineveh Province. Jornal of Biotechnology Research Center, 4(2). (2010). 
[19] H. Maleki, A. Dehnad, S. Hanifian, and S. Khani, Isolation and Molecular Identification of Streptomyces spp. With Antibacterial Activity From Northwest of Iran. Biolmpacts.,vol 3 no.(3) pp:129 - 134. (2013).

[20] N. A. Al-Dhabi, G. A .Esmail, V. Duraipandiyan, M. V. Arasu, \& M. M. Salem- Bekhit. Isolation, identification and screening of antimicrobial thermophilic Streptomyces sp. Al-Dhabi-1 isolated from Tharban hot spring, Saudi Arabia. Extremophiles, vol 20 no. (1), pp. 79-90. (2016).

[21] Y. Istianto, R. S. A. Koesoemowidodo, Y. Watanabe, H. Pranamuda, and B. Marwoto. Application Of Phenol Pretreatment For The Isolation Of Rare Actinomycetes From Indonesian Soil. Microbiology Indonesia, vol 6 no.(1),pp7-7. (2012).

[22] A. Uzel, E.H. Kocabas, and E. Bedir. Prevalence of Thermoactinomyces thalpophilus and T. sacchari strains with biotechnological potential at hot springs and soils from West Anatolia in Turkey. Turk J Biol 35:pp195-202 (2011)

[23] J. Wink, F. Mohammadipanah, J. Hamedi, Biology and biotechnology of actinobacteria: Springer; 2017.

[24] J. B. Patel, 16S rRNA gene sequencing for bacterial pathogen identification in the clinical laboratory. Molecular diagnosis, vol 6 no.(4) pp, 313-321. (2001). 